\title{
"Ynclinando la oreja del mi entendimiento". Simbología mística en Arboleda de los enfermos de Teresa de Cartagena
}

\section{"Ynclinando la oreja del mi entendimiento". Mystic Symbolism in Teresa de Cartagena's Arboleda de los enfermos}

\author{
ILSE DíAz MÁrQUEZ \\ Universidad Autónoma Metropolitana-Iztapalapa \\ ayrazul@hotmail.com
}

\begin{abstract}
RESUMEN
El tratado Arboleda de los enfermos fue escrito a mediados del siglo xv por la religiosa burgalesa Teresa de Cartagena, con la intención de mostrar un camino de sanación del alma a quienes, como ella, que había perdido el oído, padecían una enfermedad. El texto presenta rasgos propios de la literatura mística, pues expone el proceso de comprensión de una realidad interior, para la cual el espíritu debe seguir una vía en la que el sufrimiento es fundamental. El presente trabajo analiza el contenido místico de los símbolos que aparecen en el tratado, colocándolos en relación con la tradición cristiana y con la judaica, y considerando que la autora pudo recurrir a esta última gracias a su situación de judeoconversa.
\end{abstract}

Palabras clave: Teresa de Cartagena, símbolos, literatura mística española, judeoconversos

\begin{abstract}
Arboleda de los enfermos is a religious treaty written in the middle of 15 th century by Teresa de Cartagena, a nun from Burgos, after her hearing loss. In her treaty, Teresa de Cartagena attemps to show to those who also suffer from an illnes a way to heal their souls. The text presents some characteristics of mystic spanish literature, as it exposes the comprehension process of an inner reality in wich the soul needs to follow a crucial path of suffering. This paper analizes the symbolism in the treaty, from the Scholem and Lotman's perspectives about the symbol as a vehicle of tradition and mystical experience, to later explain the relationship between symbols of the Christian and Jewish traditions presented on the text. Teresa de Cartagena could have known this second tradition due to the Jewish converso origins of her family, in wich her grandfather, the ex rabine Pablo de Santa María, and her uncle Alfonso de Cartagena were counted, both prominet humanist and educated in Hebrew tradition.
\end{abstract}

KEYwORDs: Teresa de Cartagena, symbols, spanish mysticism, Jewish conversos

FECHA DE RECEPCIÓN: 13/11/2019

FECHA DE ACEPTACIÓN: 26/02/2020 
S urgidos en el complejo entramado cultural del siglo XV español, los dos tratados conocidos de Teresa de Cartagena se nos presentan tan singulares como su autora, religiosa nacida en Burgos, en el seno de una de las familias judeoconversas de mayor influencia en el pensamiento y la esfera cultural castellana del siglo: los Santa María o Cartagena. Teresa se entregó a la escritura tras haber quedado sorda debido a una enfermedad que padeciera durante su juventud, y su obra no sólo es una de las primeras obras escritas en lengua española por mano femenina, sino que también resulta insólita por el uso de una voz personal, y por la variada cantidad de elementos provenientes de la tradición clásica, de la tradición bíblica y de la patrística que estos reúnen, evidenciando que su autora poseía una formación privilegiada para una mujer de su época.

60 El primero de los tratados, Arboleda de los enfermos, se constituye como una obra de tipo consolatorio, en la cual Teresa se dirige a aquellos que como ella han perdido la salud, mostrándoles un itinerario de virtudes que les permita, a través de su sufrimiento, acercarse a Dios. El segundo tratado, Admiraçión operum Dey, es una defensa de la intelectualidad femenina, y se presenta a manera de apostilla del tratado anterior, luego de las invectivas del que éste había sido objeto por parte de algunos "prudentes varones" (Cartagena, Arboleda, 113) que no consideraban posible que una mujer, y mucho menos una mujer sorda, pudiera haber escrito una obra de tal calidad.

Si bien la crítica reciente se ha centrado, debido a la reflexión íntima que la autora inserta en los dos tratados, en interpretarlos a partir de un enfoque cercano a los estudios de género, ya indagando en la construcción de la voz femenina, ya relacionándolos con la Querella de las mujeres o con los textos de autoras paradigmáticas como Sor Juana Inés de la Cruz, también encontramos otra vertiente crítica, que se ha interesado por la naturaleza mística de los textos. Dicha vertiente parte de la consideración de que, además de estar inscritos en el ámbito de lo religioso, ambos tratados despliegan un camino para lograr el encuentro con la divinidad, que nos recuerda hasta cierto punto la vía de los místicos españoles del XVI, y también nos remiten a un proceso de conocimiento revelado, que la autora ostenta como principal argumento defensivo al momento de justificar el saber del que ha dado muestra en sus escritos.

En este sentido, los tratados se nos descubren como testimonios de una vivencia de lo divino, y Teresa de Cartagena se manifiesta entonces como precursora de Santa Teresa de Ávila. María Milagros Rivera Garretas considera que la espiritualidad contenida en Arboleda de los enfermos va más allá de "un conjunto de fórmulas para aguantar, para sobrellevar sumisamente la 
desgracia", y pasa a ser "una propuesta de salud espiritual y de paz, de recuperación de las ganas de vivir: de recuperación de un deseo (ella le llama "deseo en Dios”) que ahora se proyecta en lo infinito" (“Teresa de Cartagena”,757). Por su parte, María del Mar Cortés Timoner, considera que Teresa de Cartagena experimentó el amor divino y por tanto tuvo una experiencia mística que la colmó y liberó ("Fue levado mi entendimiento", 150-151). ${ }^{1}$

En el presente trabajo, me inclino por la perspectiva de estas investigadoras y me centro en el análisis del primero de los tratados, Arboleda de los enfermos, el cual contiene símbolos que, como me esforzaré en demostrar, son plenamente interpretables en el contexto de la tradición del misticismo cristiano, pero que además presentan, como sugirió Lewis Hutton en el estudio preliminar a su edición de los tratados, algunos rasgos del pensamiento ascético y del misticismo judío, a los cuales Teresa de Cartagena pudo estar cercana, dados sus orígenes conversos. Partiré pues de las sugerencias que Hutton apunta, y avanzaré desde allí hacia la profundización de los aspectos místico-simbólicos más sobresalientes en el texto.

\section{EL SÍMBOLO EN LA MÍ́STICA}

Resulta pertinente, antes de hacer referencia al contexto en el cual surge Arboleda de los enfermos, abordar algunos aspectos del símbolo en tanto vehículo de la tradición y de la experiencia mística. De acuerdo con Yuri Lotman, un símbolo sirve de plano de expresión para un contenido distinto, del que suele decirse que es "más valioso culturalmente" ("El símbolo", 102). El símbolo es siempre un texto, por lo cual posee un significado "cerrado en sí mismo", que nos permite distinguirlo del contexto que lo rodea y que le otorga una independencia de sentido, gracias a la cual no permanece en un corte sincrónico de la cultura, y puede proyectarse al futuro ("El símbolo", 102). Dicha operación resulta posible dado el complejo multivocalismo que los símbolos poseen, ya que no agotan nunca su significación y tienen la capacidad de concentrar gran cantidad de sentidos. El símbolo es pues portador de algo

\footnotetext{
${ }^{1}$ Los puntos de vista de estas investigadoras se contraponen a los de estudiosas como Yonsoo Kim, quien niega que los textos de Cartagena tengan características propias de la literatura mística, puesto que no hay en ellos referencia a visiones, arrobos o éxtasis; para Kim, el itinerario de los textos tiene más que ver con la enfermedad como un "proceso de construcción de la identidad del sujeto que la padece, y se sublima en actividades productivas y creativas, tanto intelectuales como espirituales" ("La discapacidad física", 22).
}

Medievalia 52:1, 2020, pp. 59-76 
arcaico y su memoria "siempre es más antigua que la memoria de su entorno textual no simbólico" ("El símbolo”, 102). Dicho contenido entra además en relación directa con las tradiciones, puesto que "la actualización, reiteración y reinvención [... ] es la dinámica de la memoria cultural” (García Peña, "Nociones esenciales", 134). Al insertarse en una determinada tradición, ya sea que provenga del pasado de la misma o de una diferente, un símbolo resurge "de la profundidad de la memoria de la cultura [... en la memoria del sujeto discursivo y se encarna en el nuevo texto" ("Nociones esenciales", 134).

Todo lo anterior resulta importante para el presente análisis, puesto que los símbolos que aparecen, que "se encarnan" en los textos de Teresa de Cartagena, no son fruto de una invención personal, sino que provienen de un determinado ámbito histórico-cultural y de las tradiciones que le eran cercanas. 62 Como mostraré en el siguiente apartado, tanto el ámbito de producción de las obras, como las tradiciones de las que la autora bebe, nos llevan a pensar en su condición de conversa y en cómo ésta habrá colaborado en la conformación de los textos.

En esta misma lógica, Gershom Scholem explica que los místicos de diversas religiones expresan su experiencia en forma simbólica, y dotan de nuevos contenidos a los símbolos de su tradición. Según Scholem, los textos místicos representan "el intento de interpretar y comunicar a los demás los caminos que han seguido los místicos, las iluminaciones que han recibido y las experiencias que han sufrido" (La Cábala y su simbolismo, 6). Los símbolos permiten al místico expresar una vivencia que es de entrada inefable, aunque ese elemento inefable está siempre condicionado por la tradición a la cual el místico pertenece y la cual conoce (La Cábala y su simbolismo, 8). En un movimiento inverso, el místico no buscaría en el repertorio de su cultura los símbolos que le permitan comunicar la experiencia, sino que la experiencia misma y sus manifestaciones estarían determinadas por los símbolos que corresponden a su tradición.

La reinterpretación simbólica realizada por el místico puede darse, bien a través de la atribución de nuevos sentidos a viejos símbolos o bien por medio de la utilización de nuevos símbolos a los que se les atribuye un significado antiguo (La Cábala y su simbolismo, 25). A partir de estas afirmaciones, me corresponde no solamente localizar cuáles son los símbolos que Teresa de Cartagena elige para dar cuenta de su experiencia, sino además indagar acerca de dónde provienen dichos símbolos y de qué manera se realiza en el texto el proceso de resignificación de los mismos.

Finalmente, es importante para esta dialéctica simbólica, el considerar la educación que el místico recibe, así como la personalidad de su guía 
espiritual. Puesto que crece dentro del marco de una autoridad religiosa, por mucho que se esfuerce en seguir un camino propio, el místico no puede "rechazar fácilmente la herencia de sus padres", ni escapar a una "herencia secular" ( $\mathrm{La}$ Cábala y su simbolismo, 16). Este último punto me lleva a interrogarme acerca de la posibilidad de que en la herencia secular de Teresa de Cartagena se encuentren elementos no sólo cristianos, sino también judaicos, lo mismo que por la eventualidad de que en la formación de la autora haya tenido influjo el trabajo y la autoridad de su abuelo y de su tío, las dos figuras intelectuales de la familia.

No tenemos noticia directa de la influencia del abuelo, quien antes de su conversión, ocurrida en la última década del siglo XIV, era conocido con el nombre de Ŝelomó Ha-Leví, respetado rabino de la judería de Burgos, y que a la postre tomaría el nombre de Pablo de Santa María, se codearía con las autoridades eclesiásticas, iría a estudiar a Roma y terminaría por ser obispo de su ciudad. Sin embargo, sí conocemos elementos que nos remiten a la probable guía intelectual del tío, Alfonso de Cartagena, quien también llegó a ser obispo de Burgos y destacó como humanista en la corte de Juan II. Sabemos del aprecio que Alfonso tenía por su sobrina por medio de un par de cartas dirigidas al Papa Nicolás V, en las cuales le solicita permiso para que Teresa se trasladara de la orden franciscana a otra en la que se encontrara más cómoda, y que se le otorgara un cargo conventual de acuerdo con la dignidad de su familia. ${ }^{2}$

\section{CANON HetEROdOXO Y HERENCIA JUdAICA}

Para matizar mi hipótesis, me apoyo en las reflexiones de Carlos Conde Solares sobre el canon de la mística española, al cual tradicionalmente se ha concebido como ortodoxo. Para este investigador, se trata en realidad de un canon heterodoxo, puesto que en todas las etapas de su construcción, lo veamos desde el punto de vista literario, sociológico o teosófico, confluyeron varias tradiciones. Evidentes podrían resultarnos las "tensiones, colaboraciones y porosidades entre las espiritualidades cristiana, sufí y sefardí durante todo el período medieval" (El canon, 9), pero más allá de eso, Conde Solares propone una diversidad de componentes culturales que también impregnaron lo que llegaría a ser la mística cristiana del Renacimiento, tales como los elementos "sufíes, orientales, lulistas, esotéricos y cabalistas", así como "los paralelismos con gnósticos y alumbrados” (El canon, 23).

${ }^{2}$ Las cartas tienen fecha de 1449 y aparecen en el Bulario de la Universidad de Salamanca (1218-1549). Tomo III, pp. 39-41 (súplicas 1111 y 1113).

Medievalia 52:1, 2020, pp. 59-76 
Un ejemplo de tal eclecticismo es el símbolo del camino de perfección, fundamental en la mística cristiana del XVI, tomado en apariencia del pseudo Dionisio y que Santa Teresa representara como el paso por las moradas de un castillo (El canon, 57). Para Conde Solares, este símbolo contiene dentro de sí "el neoplatonismo del recuerdo del alma, el ápice agustiniano, la división del alma en potencias propia del De anima aristotélico y tamizada por Avicena, y la idea mística, común en la Europa cristiana medieval, del itinerario místico formulado por Buenaventura [... ] y compartido por las sensibilidades trascendentales semíticas e ibéricas, desde Ramón Llull hasta los sadilíes y los cabalistas sefarditas" (El canon, 56). Así lo confirman las obras del sufí Ibn al-Arif de Almería (1088-1141), en las cuales se reproduce también un itinerario de las etapas necesarias para alcanzar la unión mística (Conde Solares, "Palacios 64 de cristal”, 17), equivalente a la ascensión del alma que muestra el Zohar, texto fundamental de la cábala hispanohebrea ("Palacios de cristal", 16). La España tardomedieval resulta ser pues un crisol de espiritualidades cuya glosa debe llevarse a cabo "de manera circular y conceptual, admirando incluso la fluidez y naturalidad de la interacción entre unas tradiciones que confluyen en una misma raíz, a través de un tronco común" ("Palacios de cristal”, 31). No se trata tanto de encontrar meras coincidencias, ni de permanecer en el nivel de las apariciones simbólicas arquetípicas, como de referir el contenido semántico específico de los símbolos en estas tradiciones, para así poder explicar por qué se corresponden unas con otras (López Baralt, "Simbología mística”, 25), y de advertir asimismo las relaciones históricas que dichas tradiciones mantienen.

En el caso de Teresa de Cartagena, el establecimiento de las fuentes a las que ésta recurrió resulta sumamente problemático, comenzando por el hecho de que, más allá de los hallazgos documentales hasta ahora efectuados, que arrojan luz sobre todo en lo relativo al pasado familiar y a algunos sucesos de la vida de la autora, no conocemos de su formación y de sus lecturas nada más que las mismas referencias dentro texto, y la mención que la autora hace a los años que en su juventud pasó estudiando en Salamanca ${ }^{3}$, antes de su ingreso a la orden franciscana. Sin embargo, podemos recurrir al contexto de producción de sus obras, el cual no deja de remitirnos a la huella que el judaísmo dejó en el primer humanismo español. Autores fundamentales como Bataillon o Asensio, han planteado que la exégesis bíblica proveniente de la tradición hebrea fue, junto con el conocimiento de la tradición grecolatina, el otro elemento primordial que los eruditos incorporaron a su formación,

${ }^{3}$ La autora escribe: "ca a esto no bastaría mi flaco juyzio, mas segund la pequeña facultad de aquél y los pocos años que yo estudié en el estudio de Salamanca” (Cartagena, Arboleda, 103). 
ya que una de las características principales de la intelectualidad y la espiritualidad de la época fue "su capacidad de absorber información en múltiples fuentes, para luego mezclarlas con sabiduría y ofrecer un producto original" (Fernández López, La tradición judía, 17). Tal influencia se manifestó en la recurrencia al hebreo y al arameo, así como en la práctica de la exégesis literal, propia de la hermenéutica rabínica (La tradición judía, 24).

Todo esto no hubiera sido posible sin la participación activa de los intelectuales judeoconversos y de sus discípulos, quienes renovaron con su conocimiento los métodos de interpretación y traducción de la Biblia (La tradición judía, 25-28) y quienes además de copiar, recopilar y traducir comentarios rabínicos "llenaron las más importantes bibliotecas conventuales y universitarias de esos mismos tratados que habían adquirido, en buena medida, en las más importantes aljamas hispanojudías" (La tradición judía, 29). También a lo largo del siglo xv, la utilización de los métodos cabalísticos de exégesis continuó siendo común al momento de establecer conexiones entre el Antiguo y el Nuevo Testamento; y es que la importantísima tradición de la cábala que se desarrolló en España durante los últimos siglos de la Edad Media, no sólo se mantuvo presente en las décadas anteriores a la expulsión, entre los conversos que poseían una formación hebrea tradicional, sino que alcanzó, igual que la hermenéutica judaica, a los filósofos cristianos renacentistas, muchos de los cuales se volvieron estudiosos de los textos de grandes cabalistas hispanomedievales como Raŝi, Abraham Ibn Ezra, o bien de filósofos del mismo origen, tales como Maimónides (Glatzer, “Crisis de fe”, 97).

El mismo abuelo de Teresa de Cartagena se nos muestra como ejemplo de lo anterior: en su obra Scrutinium Scripturarum (1434), escrita con el fin de presentar "una renovada comprensión de la conversión de los intelectuales judíos de aquella época" ("Crisis de fe”, 55), así como una justificación acerca de la continuidad entre la religión judía y la cristiana, el obispo Pablo de Santa María hizo uso de las Escrituras y de un caudal importante de referencias a obras judaicas como el Talmud, los Targum, los Midrashim, y de citas de filósofos judíos como Saadya Gaon, Rashi, Maimónides, Nahmánides y Gersónides ("Crisis de fe", 62). Glatzer apunta que la demostración de que la naturaleza humana y divina del Mesías coexisten sin que esto afecte a la perfección divina ("Crisis de fe", 65), ${ }^{4}$ la realiza Santa María a partir de fuen-

4 “Al discutir el versículo 'El justo es el fundamento del mundo' (Prov. 10, 25), 'Paulus' cita el Sefer ha-Bahir 157, con estas palabras: 'El Santo, Bendito Sea El, tiene sólo un justo en el mundo y es amado porque mantiene todo el mundo y lo sostiene y lo acrecienta todo', etc. Y concluye con respecto a ese solo justo: 'Y él es el fundamento de todas nuestras almas,

Medievalia 52:1, 2020, pp. 59-76 
tes judías post-bíblicas, entre las cuales destaca el Sefer ha-Bahir, el primero de los textos de la cábala hispanohebrea. Por su parte, Alfonso de Cartagena, que había nacido poco antes de la conversión de la mayoría de los miembros de la familia, había sido todavía formado en la tradición hebrea, muy probablemente por su madre, quien permaneció en la fe judía; como su padre, Alfonso dedicó su labor intelectual a justificar la continuidad histórica entre el judaísmo y el cristianismo, y a demostrar la sinceridad de la fe de los cristianos nuevos (Villacañas Berlanga, "El programa”, 50).

Una vez señalado el contexto en el cual surgen los tratados de Teresa de Cartagena, me abocaré al análisis de los símbolos que aparecen en la primera parte de tratado, la cual corresponde al exordio y a la narratio. Es esta primera parte la que nos remite a la naturaleza mística del texto.

\section{Simbología en ARboledA DE LOS ENFERMoS}

Mientras que el exordio de la obra cobra un matiz autobiográfico, puesto que en él la autora expone su vivencia de la sordera, la narratio desarrolla una reflexión acerca de la enfermedad como ruta de purificación del pecado y vía de acceso a un conocimiento interior. Veremos ahora cuáles son los símbolos que allí se despliegan.

\section{a) La isla}

Tras manifestar que el tratado ha sido escrito después de que la autora hubiera perdido el oído, el exordio comienza de este modo:

$[G]$ ran tiempo ha, virtuosa señora, ${ }^{5}$ que la niebla de tristeza temporal e humana cubrió los términos de mi beuir e con vn espeso torbellino de angustiosas pasyones me lleuó a vna ýnsula que se llama "Oprobrium hominum et abiecio plebis” donde tantos años ha que en ella biuo, si vida llamar se puede, jamás pude ver persona que endereçase mis pies por la carrera de la paz, nin me mostrase camino por donde pudiese llegar a poblado de plazeres. Asý que en este exillyo e tenebroso destierro, más sepultada que morada me sintiendo, plogo a la misericordia del muy Altýsimo alunbrarme con la luçerna de su piadosa

y esto es lo que está escrito, 'el justo es el fundamento del mundo" (Santa María, Scrutinium Scripturarum, Dist. X, Cap. IX).

${ }^{5}$ Es probable que la dedicatoria sea para la noble castellana Doña Juana de Mendoza. 
graçia, porque pudiese poner mi nombre en la nómina de aquello de quien es escrito: "Los que morauan en tiniebras y en sonbra de muerte, luz les es demostrada (Arboleda, 37-38).

La isla, cubierta por un "espeso torbellino de angustiosas pasyones", se nos aparece aquí como representación del aislamiento en el que Teresa de Cartagena ha vivido durante años, cuya desolación se remarca cuando la autora agrega el elemento de la obscuridad. No se trata sin embargo de una isla a donde vayan todos los pecadores, sino de un sitio destinado específicamente para los enfermos, imagen que cobra sentido si se atiende a la concepción medieval de las enfermedades, que se interpretaban como designios divinos, mientras que al enfermo se le consideraba elegido entre todos los pecadores, para recorrer un camino que, por medio de la imitatio Christi, lo purificara de sus pasiones (Fernández Dueñas, “Cristianismo y medicina”, 108).

El simbolismo de la isla remite a un espacio al que no se llega sino al término de un viaje por mar o por aire (Chevalier y Gheerbrant, Diccionario de símbolos, 595), así como a circunstancias de soledad y de muerte (Cirlot, Diccionario de símbolos, 254). Teresa de Cartagena apunta que ha llegado a esa isla, cuyo nombre es "Oprobio de los hombres y tristeza de los pueblos", arrastrada por un espeso torbellino hecho de angustias y de pasiones, cual si se tratara de un viaje forzoso al final del cual no encuentra vida, ni placeres: la isla, más que una morada, es una sepultura. El viaje a dicha isla equivale también a un exilio, puesto que no es el enfermo quien elige su padecimiento, sino Dios quien se lo entrega como oportunidad de alcanzar la vida eterna.

En su introducción a los tratados, Hutton retoma las afirmaciones de Américo Castro sobre la recurrencia del tema de la huida del mundo y el desdén de los honores humanos en la literatura judeoespañola, para aludir a la presencia de dicha tradición en las obras de la monja. De ahí puede desprenderse una posible relación de este primer símbolo con la idea del exilio en el judaísmo. De acuerdo con la cábala hispanohebrea, el exilio forma parte de la creación y más allá de presentarse como una prueba o un castigo para los hombres, es una misión que debe cumplirse para que el alma humana pueda liberarse de sus ataduras terrenas, elevarse hacia la luz divina e integrarse en el todo cósmico (Muñiz-Huberman, Las raíces y las ramas, 79). El pueblo judío es desterrado para que sus habitantes puedan aspirar al perfeccionamiento de su alma; en este proceso, cada ser debe procurar salvarse a sí mismo pero también salvar a sus prójimos (Las raíces y las ramas, 79), de la misma forma en que Teresa de Cartagena, al buscar un consuelo para su propia situación, elige compartir su experiencia con otros enfermos. 
Así como en términos cabalísticos, el exilio permite el acceso a la luz, y acaba por mostrar a los hombres "las fuentes ocultas de la sustancia vital de la creación” (Las raíces y las ramas, 79), así para la autora, las tinieblas de la enfermedad pueden ser disipadas por la iluminación divina, lo que le permite entender su experiencia y hacer de ella una vía de redención. El exiliado que se separa dolorosamente de lo familiar y que debe recomenzar su vida se ve impelido a interrogarse y a intentar explicar el sentido de su destierro (Las raíces y las ramas, 70); del mismo modo, Teresa de Cartagena se cuestiona el sentido de su enfermedad y se propone escribirlo para que otros puedan entenderlo también.

\section{b) El árbol y la arboleda}

68 El símbolo de la isla da paso a la imagen de las "arboledas de buenos consejos y espirituales consolaçiones” (Cartagena, Arboleda, 38). La autora se dirige a los enfermos para explicarles la intención de su obra; busca consuelo en el Salterio de David, y allí encuentra amonestaciones y consejos que le ayudan, una vez disipadas las tinieblas, a llenar su soledad "de arboleda graçiosa, so la sonbra de la cual pueda descansar mi persona y reçiba mi espíritu ayre de salud" (Arboleda, 38). Teresa compara el contenido de su tratado con un sitio lleno de árboles, un lugar agradable que ofrece refugio de los sufrimientos y donde se pueden encontrar buenos consejos para obtener la salud del alma, que debe buscarse siempre por encima de la salud corporal.

En la tradición judeocristiana, el árbol simboliza la vida del espíritu y se manifiesta como "protector en razón de su sombra" (Chevalier y Gheerbrant, Diccionario de símbolos, 125). Este simbolismo adquiere un matiz místico en los relatos de visiones medievales cristianas, como sucede en el Poema de Santa Oria de Berceo, ambientado en la madrugada de la fiesta de Santa Eugenia del año 1068: en él leemos que a la santa, quien va a dormir luego de haber escuchado los maitines, se le presenta la visión de tres vírgenes mártires, Ágata, Eulalia y Cecilia, quienes llevan palomas en sus manos y le dicen que la llevarán al Cielo. Santa Oria sube con ellas por una escalera altísima al final de la cual hay un árbol y figuras angélicas vestidas de blanco (Uría, “El árbol”, 116-117). La imagen de la arboleda responde pues asimismo al tópico del locus amoenus, ${ }^{6}$ que con sus prados, fuentes y arroyos, recuerda al Paraíso terrenal.

${ }^{6}$ Así lo vemos en los versos introductorios de los Milagros de Nuestra Señora: "Yo, maestro Gonçalvo de Verceo nomnado / yendo en romería caecí en un prado / verde e bien sentido, de flores bien poblado / logar cobdiciadero para onme cansado" (Berceo, Los Milagros de Nuestra Señora, LIX, p. 3). 
Según Hutton, la imagen de una arboleda donde se pueden encontrar buenos consejos proviene de la obra del francisano del siglo XIII, Ramón Llull, quien fue el primero de los místicos cristianos en tratar de incorporar a su religión la sabiduría de la cábala hebrea. Llull recurrió con insistencia al simbolismo del árbol sefirótico, cuyas ramas son las diez sefirot o emanaciones divinas, en la que se origina el orden de la creación, y transformó estas emanaciones en dignitates Dei capaces de contener el conocimiento humano de cualquier campo. Dicho árbol aparece en dos textos paradigmáticos de la cábala hispanohebrea: en el Séfer ha-Bahir o Libro de la claridad, en el cual "las potencias de Dios están dispuestas en capas o ramas como en un árbol que produce frutos gracias a los elementos. Dios, por medio del agua, aumenta el poder del árbol. El agua, emanación divina, equivale a la sabiduría" (Muñiz-Huberman, Las raíces y las ramas, 142). En el Zohar o Libro del esplendor, por su parte, las hojas del árbol de la muerte simbolizan el saber mágico, que es una de las consecuencias de la caída del hombre, y razón por la cual el cuerpo físico queda privado de la luz (Guénon, Símbolos, 316).

En su obra Árbol de la ciencia, Llull hace uso del tópico del locus amoenus de forma similar que en la Arboleda, colocándose a sí mismo como el personaje que allí encuentra consuelo: "En desconsuelo y en llantos estaba Ramon bajo un bello árbol, y cantaba su desconsuelo, para alejar un poco su dolor" (Vega Ezquerra, Ramón Llull, 207). Sin embargo, no es solamente alivio lo que el lugar le proporciona a Llull, hay también un hallazgo de conocimiento, y así, el autor hace desfilar frente a nosotros un árbol de la ciencia, un árbol de la medicina, un árbol de la religión: en "el Libro de las maravillas el árbol ofrece a cada quien que lo contemple en actitud mística el esplendor de las dignitates Dei” (Muñiz-Huberman, Las raíces y las ramas, 141), mientras que en el Árbol ejemplifical, "se vale del arte combinatoria para establecer la correlación entre las emanaciones divinas, los elementos, la escala del ser, los humores, las verdades cristianas y la estructura del árbol en sí” (Las raíces y las ramas, 142).

Como dos siglos antes lo hiciera Ramón Llull, Teresa de Cartagena concibe su arboleda como un lugar donde se encuentra el consuelo pero también el conocimiento. No se trata de un conocimiento del mundo, el cual, debido a su sordera, ella ha dejado de percibir, sino de la revelación divina, revelación que le abre la comprensión sobre el sentido de su enfermedad y transfigura su alma, devolviéndole la tan deseada salud espiritual.

c) El oído

La aparición de este elemento, representado por el órgano exterior, la oreja, marca el paso hacia la narratio, en la cual Teresa de Cartagena explica la 
manera en que su enfermedad la alejó del mundo, y la obligó a voltear hacia los asuntos espirituales. Tal paso lo ilustra metafóricamente:

E paresçe aver acaesçido a mí lo que vehemos acaesçer quando fablan muchos en vn tropel y les paresçe que en otra parte oyen bozes. Ca fazen señal con la mano porque callen y escuchen, en ansý tienen sylençio por mejor poder entender las bozes $[\ldots] \mathrm{E}$ algunos ay, que no atendiendo prudentemente que aquel fin porque les manda $[\mathrm{n}]$ callar $[\ldots]$ no dexan por eso de palabrear. Pero si entr'ellos está algund onbre discreto e conosçe que aquellas bozes trahen algund prouecho $[\ldots]$ señala con el dedo en la boca, e asýles da a entender que les cumple callar [... E avnque les pesa, tienen silençio, mayormente si el que faze estas señas es persona a quien deuen temor e obidençia (Arboleda, 40).

De ese modo, dice Teresa haber estado envuelta "en el tropel de las fablas mundanas", y su entendimiento "bien revuelto" y "atado" a ellas; entonces la mano de Dios le hizo señal de "que callase y çesase las hablas mundanas” (Arboleda, 41), y así ella calló por fuerza. Esta escucha forzosa tiene que ver, por supuesto, con el inicio de su sordera, cuando deja de escuchar los ruidos exteriores y comienza a escuchar y a tratar de comprender las realidades interiores.

El oído simboliza en la tradición cristiana "la obediencia a la palabra divina”,la aceptación y comprensión de sus designios, cuyo paradigma es el momento de la anunciación, en el cual María acepta libremente y entiende el misterio de concebir al Mesías; la oreja es pues el órgano de la comprensión (Chevalier y Gheerbrant, Diccionario de símbolos, 781). Cuando poseía ese sentido, Teresa "no podía oýr las bozes de la santa dotrina que la Escritura nos enseña e amonesta" (Arboleda, 44); sin embargo, una vez que ha sido apartada de las voces humanas, es que puede "inclinar la oreja de su entendimiento", y esforzarse por entender las palabras divinas.

El aspecto pasivo del oído, receptor del mensaje sagrado, se confirma en San Pablo, quien afirma que la fe se recibe por audición (fides ex auditu) (Chevalier y Gheerbrant, Diccionario de símbolos, 782). Lo paradójico en Teresa de Cartagena, como en la mayoría de los místicos cristianos —aunque en ella de forma total y permanente-, es que el silencio sea una condición obligada y necesaria para escuchar, para acceder a la revelación. Para los primeros anacoretas cristianos, el silencio ocupaba un lugar muy importante en el proceso ascético: apartados en las soledades de los desiertos de Siria y Egipto, se dedicaban a abrir el corazón a la escucha, en espera de la revelación y de la metanoia, la conversión del alma (Apotegmas, 36). 
Al buscar ecos de la literatura medieval hispanohebrea en los tratados de Teresa, Hutton se remite al pensamiento del filósofo Ibn Gabirol (10211070), quien habló de los cinco sentidos humanos; entre ellos, el oído es el que más influye en el alma, y sólo aquellos que son disciplinados se abstienen de oír lo que no es saludable (Gabirol, The Improvement of Moral Qualities, citado por Hutton, Arboleda, 35). Gabirol se expresa en términos de salud, exactamente de la misma forma en que Teresa lo hace: “ $i \mathrm{O}$ marauillosa caridat del Señor soberano, que tan manifiestas señales me muestra[s] para que escuche lo que a mi salud es neçesario..." (Arboleda, 43), siendo igualmente condición del bienestar espiritual, el padecimiento físico.

Maimónides, el gran filósofo y médico judío del siglo XIII, interpreta en su Guía de los perplejos el verbo shamá, que significa oír, escuchar, comprender, pero también obedecer. Aplicado a Dios, shamá cobra el sentido de perfección y de la percepción de la ciencia (Guía de los perplejos, 154). Por su parte, la cábala hispanohebrea señala que el lenguaje divino parte de una esencia interna hacia un sonido inaudible y luego hacia la articulación del habla: "Oír el álef" es lo mismo que no oír nada: es la preparación para todo lenguaje audible". Así, la cultura judaica se nos aparece más atenta al sentido de la audición y a revelación que se da por medio del oído, en contraposición a la cultura grecolatina, más centrada en lo visual, característica que hereda el cristianismo, para el cual la revelación se da generalmente a través de la visión (Muñiz-Huberman, Las raíces y las ramas, 61). De igual modo, para Teresa de Cartagena, el conocimiento parte de lo inaudible, del silencio, para luego dar forma a una comprensión de lo misterioso, a una revelación que no es visual sino aprehensible a través "de la oreja del entendimiento".

\section{d) La casa, la ciudad, la fortaleza}

Estos tres símbolos, que se constituyen como espacios bien delimitados, aparecen enlazados por medio de una "sintaxis simbólica" de tipo compositivo, es decir modificándose entre ellos por su vecindad para dar lugar a un

\footnotetext{
${ }^{7}$ Según el Zohar, cuando Dios quiso crear el mundo, las letras, que se encontraban ocultas, se presentaron ante él, de manera que pudiera decidir con cuál de ellas comenzar la creación; álef, sin embargo, se quedó en su lugar, pensando que su presencia sería inútil. Sin embargo, Dios la compensó: "ya que serás la primera de todas las letras y yo no encontraré unidad sino en ti; tú serás la base de todos los cálculos, de todos los actos que se realicen en el mundo, y no se podrá encontrar la unidad en ninguna parte si no es en la letra Alef” (Zohar I, 2b-3b).

8 "El álef denota el origen de todo sonido articulado y para los cabalistas representa la raíz espiritual de todas las letras” (Muñiz-Huberman, Las raíces y las ramas, 25).
}

Medievalia 52:1, 2020, pp. 59-76 
significado más complejo, aunque el sentido de cada uno de ellos no se altere (Cirlot, Diccionario de símbolos, 46). Una vez que Teresa ha inclinado el oído al entendimiento de las cosas divinas, las palabras que escucha resonar son: "Oye fija, e acata e ynclina tu oreja, oluida el pueblo tuyo e la casa de tu padre", de las cuales se desprenderá una exégesis que ha sido considerada por autores como Márquez Villanueva como una clara huella del estatus de conversa de la autora. ${ }^{10}$

La problemática de la exégesis que Teresa hace del salmo reside en que la interpretación cristiana tradicional no se refiere a la casa como "los hedifiçios o çircuyito de la casa en que mora”, ya sea pequeña o grande, sino que debe entenderse como "la familia e multitud de gente" (Arboleda, 44). Teresa de Cartagena piensa que Dios no pediría que olvidáramos ni que aborreciéramos a nuestro padre ni a nuestra familia, pues esto contradiría al mandamiento que indica honrar a los progenitores; por ello es que interpreta el símbolo de la casa como "la turba multa de las cobdiçias tenporales e humanas" (Arboleda, 45).

El lugar donde habita la multitud es también la ciudad, en la cual, si algunos de sus habitantes se levantan en armas, el resto se movilizará para calmarlos, y la pequeña parte que se había levantado terminará siendo la que corre peligro. La ciudad aparece simbolizando nuestra conciencia: si una parte de ella, apegada a los placeres temporales y a la codicia se subleva para hacer daño a nuestra alma, será rápidamente sofocada por el resto de nuestra voluntad, que sigue apegada a las cosas divinas. La interrelación compositiva permite integrar a la casa y a la ciudad en un mismo conjunto de significación: ya que la casa simboliza a la multitud que habita la ciudad, y que la ciudad simboliza a la conciencia, la multitud pasa a representar las inclinaciones buenas y malas de la voluntad humana.

La composición se vincula al mismo tiempo con el simbolismo del paisaje, en el cual la ciudad terrena es un reflejo de la Jerusalén celestial (Chevalier y Gheerbrant, Diccionario de símbolos, 309). Se trata pues de una geografía sacra que presupone que la fundación de una ciudad tiene que ver con la fundación de una doctrina y con los seguidores —el pueblo- que están dispuestos a defenderla (Cirlot, Diccionario de símbolos, 133); los muros de la ciudad se corresponden con tal defensa (Cirlot, Diccionario de símbolos, 134).

\footnotetext{
9 "Audi, filia, et vide, et inclina aurem tuam; / Et obliviscere populum tuum, et domum patris tui" (Salmos, 44, 10) (Cartagena, Arboleda, 44).

${ }^{10}$ Los tratados de la monja parten "de una firme base de orden patrístico y escriturario, con enfática predilección por el viejo Testamento y dentro de éste por un recurso continuo a los Salmos de David y a la invocación del Libro de Job” (“Cartagena y Ávila: las dos Teresas”, 36).
} 
Ligados a esta última imagen está la fortaleza o castillo; Conde Solares y López-Baralt, coinciden en que este es uno de los símbolos más famosos en la mística peninsular de las tres religiones. ${ }^{11} \mathrm{El}$ castillo aparece continuamente como un refugio interior, "la caverna del corazón", el "lugar de comunicación privilegiado entre el alma y la divinidad" (Chevalier y Gheerbrant, Diccionario de símbolos, 506). Es posible ligar la idea del refugio interior con la observación de Hutton, quien relaciona la constante alusión que Teresa de Cartagena hace al aislamiento al que la recluye su enfermedad, con el ascetismo judaico, ya que debido a las continuas persecuciones y expulsiones del pueblo hebreo - que son a su vez reflejo de la expulsión de los hombres del paraíso-, éste tiende a considerar especialmente a aquellos que están marginados de la sociedad y establece entonces en el interior del sujeto el hogar que el destierro le ha arrebatado (Arboleda, 34).

Como he apuntado, para el judaísmo este exilio terrenal se corresponde con el exilio cósmico que la humanidad sufre a partir de la caída. En la cábala, el exilio cósmico da lugar a la concepción de la shejiná, la última de las sefirot o emanaciones divinas que conforman el árbol cabalístico al que antes me he referido. Según el Zohar, la shejiná debe entenderse como la morada interior de Dios en el mundo, presencia divina que cada uno debe llegar a descubrir (Muñiz-Huberman, Las raíces y las ramas, 71 ). La cábala identifica al "Santo Palacio" con la morada del corazón, donde lo divino se manifiesta; el palacio es llamado también “Templo de Jerusalén”; desde esta perspectiva, el Templo se reconstruye en el corazón de los hombres justos y la shejiná viene a residir en ellos a pesar de que se encuentren en el exilio que es el mundo. ${ }^{12}$

\section{CONCLUSiones}

Tras avanzar por estos cuatro estadios simbólicos que se presentan en la primera parte de la Arboleda de los enfermos, es posible retornar a las reflexiones de Scholem para afirmar que, desde el punto de vista de una dialéctica simbólica

\footnotetext{
11 "Se trata de un verdadero lugar común en la literatura sufí: Algazel en su Ihya' alude repetidamente al castillo espiritual cuyas puertas hay que defender del asalto del diablo” (López Baralt, "Simbología mística”, 88).

12 “Todos los mensajes que el Rey supremo envía aquí abajo, llegan por mediación de la Shekinah; y todos los mensajes que el mundo inferior manda al Rey llegan a la Shekinah, que los transmite al Rey. Así tenemos que la Shekinah es la intermediaria al mundo de arriba para responder al de aquí abajo, y viceversa" (Zohar III, p. 50b-51a).
}

Medievalia 52:1, 2020, pp. 59-76 
en la cual el autor místico, sin abandonar su tradición, innova y transgrede, Teresa de Cartagena recupera símbolos judeocristianos y los reinterpreta en el marco de su situación de monja conversa, apartada del mundo al perder la audición. La finalidad de tal recuperación es dar cuenta de un proceso de conocimiento interior, que conlleva comprender el sentido de su enfermedad como parte de un designio divino, así como de una transformación espiritual en la cual la enfermedad misma se muestra como una ruta cuyo destino es el encuentro con Dios.

De igual forma, luego de analizar el contenido de dichos símbolos, y de revisar las filiaciones de éstos con la tradición cristiana y con la judaica, en medio de un contexto en el cual tanto la mística como el humanismo del siglo $\mathrm{xv}$ bebieron de las fuentes hebreas gracias a la activa participación de 74 los intelectuales conversos, entre los cuales se contaban varios miembros de la familia Cartagena, los vínculos que Arboleda de los enfermos establece con la tradición secular a la que pertenece su autora resultan más claros. Aunque no puede asegurarse que Teresa acudiera de primera mano a las fuentes hebreas a las que he hecho referencia, el contenido semántico de los símbolos que elige no deja de remitir a un conocimiento, ya directo, ya por mediación de otros personajes, de los textos y de la tradición de la cual abrevaba su familia antes de su conversión y aún, como hemos visto, después de ella.

En modo alguno es mi intención plantear que existan en los tratados de Teresa de Cartagena atisbos de criptojudaísmo, pero no me parece improbable que la autora se haya interesado por sus orígenes, intentado una síntesis entre éstos y la nueva religión familiar, de modo análogo a su abuelo y a su tío, siendo el resultado la inclusión de elementos heterodoxos en su obra. Esto fue posible porque el clima social y cultural de Castilla, a mediados del siglo XV era todavía, hasta cierto punto, propicio para los conversos, quienes a pesar de haber comenzado a sufrir la marginación que finalmente desembocaría en la persecución inquisitorial, gozaban aún de un status importante en las esferas públicas, y su producción intelectual no sufría la censura de la cual sería objeto apenas unos años más tarde. En este ambiente relativamente propicio, en el cual el eclecticismo religioso medieval seguía dando sus frutos, se gestaron obras como las de Teresa de Cartagena, que dan cuenta de la imposibilidad de estudiar las tradiciones y los textos literarios a los que dan lugar, sin pensarlos en contacto los unos con los otros. 
Ilse Díaz Márquez

\section{BIBLIOGRAFÍA}

Apotegmas de las madres del desierto, Palma de Mallorca: José de J. Olañeta Editor, 2006.

Berceo, Gonzalo de, Milagros de Nuestra Señora, ed., de Fernando Baños, Barcelona: Crítica, 1997.

Bulario de la Universidad de Salamanca (1218-1549). Tomo III, ed., de Vicente Beltrán de Heredia, Salamanca: Universidad de Salamanca, 1967.

Cartagena, Teresa de, Arboleda de los enfermos. Admiraçión Operum Dey, ed. e introd. de Lewis Hutton, Madrid: Anejo XVI del Boletín de la Real Academia Española, 1967.

Chevalier, Jean y Alain Gheerbrant, Diccionario de símbolos, 6a ed., Barcelona: Herder, 1999.

Cirlot, Juan Eduardo, Diccionario de símbolos, Barcelona: Siruela, 1997.

Conde Solares, Carlos, El canon heterodoxo de la gran mística hispánica: beatas, mediación e iluminismo, Oviedo: Universidad de Oviedo, 2017.

Conde Solares, Carlos, "Palacios de cristal, patios interiores, árboles devocionales: simbología y espacios compartidos entre el sufismo andalusí y la mística del Carmelo", Anaquel de Estudios Árabes, 29, 2018, 9-31.

Cortés Timoner, María del Mar, "Fue levado mi entendimiento: Teresa de Cartagena y la escritura mística en femenino”, Scripta. Revista de Internacional de Literatura i Cultura Medieval i Moderna, 8, 2016, 148-163.

Fernández DueñAs, Ángel, “Cristianismo y medicina”, en Patrimonio inmaterial de la Cultura Cristiana, San Lorenzo del Escorial: Instituto Escurialense de Investigaciones Científicas y Artísticas, Simposium, 21, 2013, 105-118.

Fernández López, Sergio, El Cantar de los Cantares en el humanismo español. La tradición judía, Huelva: Universidad de Huelva, 2009.

García Peña, Lilia Leticia, "Nociones esenciales para el análisis de los símbolos en los textos literarios", $452^{\circ} \mathrm{F}$. Revista de Teoría de la Literatura y Literatura Comparada, 6, 2012, 124-138.

Glatzer, Michael, "Crisis de fe judía en España a fines del siglo xiv y principios del xv”, en Ángel Alcalá (ed.), Judíos. Sefarditas. Conversos. La expulsión de 1492 y sus consecuencias, Valladolid: Ámbito Ediciones, 1995, 55-68.

GuÉNon, René, Símbolos fundamentales de la ciencia sagrada, Madrid: Paidós Ibérica, 1995.

KIM, Yonsoo, "Discapacidad física como medio intelectual y espiritual femenino: Sor Teresa de Cartagena en la Arboleda de los enfermos", Medievalia, 38, 2006, 22-32.

López Baralt, Luce, "Simbología mística en San Juan de la Cruz y en Santa Teresa de Jesús”, Nueva Revista de Filología Hispánica, 30:1, 1981, 21-91.

Medievalia 52:1, 2020, pp. 59-76 
Lotman, YURI, "El símbolo en el sistema de la cultura”, en La semiosfera I. Semiótica de la cultura y del texto, Madrid: Cátedra, 1996.

Maimónides, Guía de los perplejos I, México: Conaculta, 1993.

Márquez Villanueva, Francisco, “Cartagena y Ávila: las dos Teresas”, eHumanista. Conversos, 2, 2014, 35-53.

Muñiz-Huberman, Angelina, Las raíces y las ramas. Fuentes y derivaciones de la cábala hispanohebrea, México: Fondo de Cultura Económica, 1993.

Rivera Garretas, María Milagros, “Teresa de Cartagena: la infinitud del cuerpo”, Acta Historica et Archeologica Mediaevalia, 20-21, 1999, 755-766.

Santa María, Pablo de, Scrutinium Scripturarum / per Reuerendissimum D.D. Paulum de Santa Maria, quondam Episcopum Burgensem...; recognitum ac restitutum per Magistrum F. Christophorum Sanctotisium ... cui addita est ipsius D.D. Pauli vita praeclara...; insuper praeludium operis, seu opusculum, de vera haereticorum origine agnoscenda, omnia ab eodem Magistro F. Christophoro Santotisio lucubrata... Burgis, apud Philippum Iuntam, 1591.

Scholem, Gershom, La Cábala y su simbolismo, 10a ed., México: Siglo XXI, 1998.

Sefer ha-Bahir. El libro de la claridad, 2a ed., trad. de Mario Satz, Barcelona: Obelisco, 1992.

URÍA, ISABEL, "El árbol y su significación en las visiones medievales del otro mundo", Revista de Literatura Medieval, 1, 1989, 103-122.

Vega Esquerra, Amador, Ramón Lllull y el secreto de la vida, 3a ed., Madrid: Siruela, 2016.

Villacañas Berlanga, José Luis, "El programa de traducciones de Alfonso de Cartagena y la Fundación de la Mentalidad Castellana”, en Alfonso de Cartagena, Los Cinco Libros de Séneca, Murcia: Tres Fronteras, 2012.

Zohar. Libro del esplendor, $3^{\mathrm{a}}$ ed., trad. de Esther Cohen, México: Conaculta, 2010. 